\title{
As questões econômicas da governança da paisagem ${ }^{(1)}$
}

\author{
WALID OUESLATI(2)
}

\section{RESUMO}

O lugar que a paisagem ocupa no debate público é reflexo de uma preocupação crescente sobre os modos de ocupação do espaço e as mudanças nos mundo rural e urbano. Ela é também a marca de um valor econômico da diversidade de paisagens por nobres atores. A disciplina econômica se encontra naturalmente solicitada. O objetivo desse artigo é de apresentar algumas ferramentas da análise econômica utilizada para tratar da problemática ligada a paisagem e participar da construção de instrumentos de governança.

Palavras-chave: externalidade, direito de propriedade, bem público, governança, planejamento espacial, economia pública, custobenefício.

\section{RÉSUMÉ \\ Les enjeux économiques de la gouvernance du paysage}

La place qu'occupe le paysage dans le débat public est le reflet d'une préoccupation croissante sur les modes d'occupation de l'espace et les mutations des mondes rural et urbain. Elle est aussi la marque de la valeur économique de la diversité des paysages pour de nombreux acteurs. La discipline économique se trouve ainsi naturellement sollicitée. L'objet de cet article est de présenter quelques outils de l'analyse économique utilités pour traiter des problématiques liées au paysage et participer à la construction des instruments de gouvernance.

Mots clefs : externalité, droits de propriété, bien public, gouvernance, aménagement du territoire, economie publique ; coûtsavantages.

\section{ABSTRACT \\ The economics stakes of the landscape governance}

Landscape provides amenities and support recreational and tourism activities, it appears both as an economic resource and as a local public good. Landscape economics could benefits from both public economics concepts and methodology. Moreover, as a new field, Landscape Economics emphasizes the role of enforcement of property rights' devices in the Landscape formation. The aim of this paper is to present some analytical tools to study economic issues related to Landscapes. Facing divided ownership issues and public policies external effects, the Landscape' governance should make use of various instruments and methods in order to provide socially optimal level of landscapes' quality and diversity.

Keywords : externality, property rights, public good, governance, spatial planning, public economics, costs-benefits.

\section{INTRODUÇÃO}

A paisagem é em muitos aspectos, uma construção política, cultural e econômica das relações que as sociedades humanas têm com o espaço. Com o tempo, gradualmente a paisagem passou a participar dos paradigmas de planejamento do território, e com isso se manifestou também nas questões sóciopolíticas do nosso tempo (PRICE, 1978, LUGINBUHL, 2004; 2007).

A ciência econômica se interessou pela paisagem desde que esta faz parte dos componentes fundamentais do bem-estar social. Apesar do interesse demonstrado pelos economistas para as questões de espaço e do ambiente, a reivindicação de uma economia dedicada à paisagem é relativamente recente. Vários trabalhos da década de 1980 tratando com a demanda social para as amenidades paisagísticas têm sido desenvolvidos nos campos da economia ambiental, ou de uma forma significativamente diferente nos campos da geografia econômica e urbana (LIFRAN e OUESLATI, 2007). O desejo de construir a economia da paisagem como uma disciplina independente surgiu recentemente nos trabalhos promovidos pela Convenção Européia da Paisagem ${ }^{(3)}$.

O valor econômico da paisagem como fonte para a economia local e como quadro de vida das populações já é conhecido, como evidenciado pelas legislações nacionais comunitárias e mesmo iniciativa globais (TURPIN e

${ }^{(1)}$ Traduzido do original em francês por João Maurício Cavalcante Alves

(2)AGROCAMPUS OUEST - UMR GRANEM, 2 rue le Nôtre - 49000 ANGERS. Contact: walid.oueslati@agrocampus-ouest.fr

${ }^{(3)}$ Assinado em 2000, a Convenção Européia da Paisagem é uma iniciativa da Conferência de Poderes Locais e Regionais, de servir ao Parlamento Europeu em Strasbourg. Sua história é uma revelação da dimensão do bem público local ligado à paisagem. 
OUESLATI, 2008). No entanto, a implementação de políticas de paisagem e a governança das paisagens enfrentam duas dificuldades principais:

- Como identificar as preferências dos cidadãos e calcular sua disposição de pagar por uma proposta ou projeto de organização do espaço?

- Como envolver os proprietários fundiários e superar a falta de coordenação das políticas publicas para implementar uma política da paisagem?

São sobre as causas destas duas dificuldades que desejamos nos aprofundar nesta comunicação.

\section{A AVALIAÇÃO DA PAISAGEM: PORQUE E COMO?}

Devido a paisagem ter o caractere de um bem público local, as modificações paisagísticas decorrentes de ações privadas ou coletivas nos usos do espaço podem ser avaliadas por métodos econômicos aplicáveis aos bens públicos. De fato, sendo um bem público, caracterizado pela impossibilidade ou dificuldade de exclusão, a paisagem não tem valor de mercado. Nestas condições, sobre quais informações sustentar a decisão coletiva, e qual procedimento utilizar para decidir se o projeto deve ser implantado ou se as mudanças devem ser contidas ou encorajadas? Esses dois problemas, de informação e procedimento, são bem conhecidos em economia pública e constituem a base do que chamamos de "a concepção de mecanismos (mechanism design)". O resultado essencial desses trabalhos é que não existe nenhum "mecanismo" capaz de satisfazer simultaneamente as propriedades informativas, estratégicas e financeiras desejáveis (mecanismo revelador das verdadeiras preferências, resistente as desvios e coalizões, equilibrado orçamentariamente...) tanto que não podemos nem de um jeito nem de outro assegurar um controle de acesso ao bem público.

Na prática da avaliação ambiental, o conhecimento da distribuição de preferências (traduzidas em disposição a pagar ou em consentimento a receber dentro do quadro da economia do bem-estar), resta ao menos a primeira etapa para embasar um procedimento de decisão. Ela alimenta a análise custo beneficio do projeto: se a soma dos benefícios (incluindo a soma das disposições a pagar) é superior a somas dos custos, supomos que o projeto pode ser implantado. Mas nesse caso, é possível que alguns envolvidos vejam seu bem-estar diminuir. Em corolário, transferências financeiras podem ser desejadas em seu beneficio (MARSHALL, 2004).

A questão que abordamos agora é a dos métodos usados pelos economistas para ter acesso ao conhecimento das disposições a pagar e sua distribuição.

De fato, a avaliação econômica da paisagem é estruturada por dois grandes tipos de métodos que revêem tanto a diferenças de definição e percepção da paisagem quanto a puras diferenças de método. Trata-se de uma parte de preferências reveladas (OUESLATI et al., 2008a, CAVAILHÈS et al., 2007) que são fundadas sobre a hipótese de uma complementaridade fraca entre os bens e serviços comerciais específicos (transportes, imóveis principalmente) e as características da paisagem, e de outra parte, as preferências declaradas (OUESLATI et al., 2008b, RAMBONILAZA, 2004), entre as quais submetemos a uma amostra representativa das pessoas de um projeto explicito de transformação da paisagem. Nenhum dos dois métodos é isento de limites e de tendências. Mas eles permitem ao menos camuflar a falta de valor da paisagem e de contrabalançar os ganhos associados às mudanças, muito mais freqüentemente medidos em valor monetário.

As definições "representacionais" da paisagem, que destacam a percepção estética ou sobre a elaboração de normas culturais, mesmo sobre o caractere ideológico de representações da paisagem, não constituem para a economia uma dificuldade, ao contrario. Elas são coerentes com o individualismo metodológico que constitui o alicerce da economia. O modelo da racionalidade individual com o qual os economistas trabalham geralmente postula que os indivíduos têm preferências que são representadas e estáveis, e que constituem uma característica do individuo (WILLINGER, 1996). A priori não tem nada de mal de integrar uma concepção "representacional" da paisagem. Ao mesmo tempo, as dificuldades aparecem, por exemplo, quando se trata de avaliar mudanças da paisagem induzidas pelo desenvolvimento de novas tecnologias. A percepção e avaliação de tal paisagem não podem ser efetuadas através de filtros de preferências elaboradas por paisagens mais "tradicionais", quer dizer correspondentes a um estado especifico do desenvolvimento tecnológico e de infra-estruturas.

A emergência de novos usos do espaço, ou de novos modos de transporte sobre a pressão do desenvolvimento econômico induz frequentemente a situações nas quais podemos ver aparecer duas questões: a da heterogeneidade e da distribuição das preferências paisagísticas, de uma parte, e a da sua formação e transformação, de outra parte. As duas questões são evidentemente difíceis a dissociar, na medida onde, quando um projeto de mudança, ou uma nova tecnologia tendo um impacto paisagístico se desenvolve, é raro que um consenso possa sair imediatamente. As discussões e oposições que cercam os novos desenvolvimentos são inevitáveis, e testemunham a heterogeneidade das percepções e avaliações individuais. A avaliação econômica se torna mais delicada, diminuindo a pertinência informacional de um valor médio para a tomada de decisão publica. Mais fundamentalmente, a validade dos métodos de avaliação pelas preferências declaradas num contexto novo e provavelmente sujeita a uma referencia construtivista importante, o questionário constituindo ele próprio um quadro de informação que contraria as preferências declaradas. Somos então conduzidos a colocar protocolos adaptados para controlar o efeito das informações obtidas sobre o projeto sobre as avaliações individuais e sua distribuição.

A experiência da gestão de projetos de impacto paisagístico (restauração de zonas úmidas, projetos de fazendas eólicas, reagrupamentos,...) ou a das transformações difusas induzidas por inovações como as culturas energéticas, o armazenamento do carbono ou o desenvolvimento das eólicas, demonstra que a maneira que o projeto é apresentado à população ou aos interessados, mais a condição da conferencia, e finalmente a execução, influenciam profundamente sua aceitabilidade. Em 
quais condições de avaliação ex ante de preferências pode ela ser útil para o gestor do projeto? Como pode ela integrar o fato que a distribuição de preferências possa ser modificada pelo procedimento da conferencia, e que inovações paisagísticas possam sair desse procedimento? Como uma maioridade ou um consenso se estabelecem em favor de um projeto? Além dessas questões, se a disposição de medidas monetárias de bem-estar associadas aos projetos de mudança é indispensável, ela não é suficiente, já que freqüentemente um projeto de conservação ou uma política paisagística se prende a duas dificuldades maiores que são de uma parte, a racionalidade dos atores titulares de direitos de uso do espaço, e de outra parte, o numero e o poder incitativo das políticas setoriais que afetam suas decisões.

\section{AJUNTAMENTO DE PRODUÇÃO E PRODUÇÃO CONJUNTA DA PAISAGEM}

Supondo que a fase de avaliação tenha permitido de identificar as preferências dos cidadãos em matéria de organização ou de transformações paisagísticas, a primeira pergunta à qual deve responder a autoridade encarregada de sua realização é a da coordenação e da agregação das ações de uma multidão de proprietários. Esse problema é aquele conhecido em economia pública com o nome de produção junta de um bem público. O segundo problema encontrado pela autoridade pública é o da coordenação de políticas publicas que tratam sobre as decisões dos titulares dos direitos do uso do espaço. Efetivamente, a potencia das incitações dadas aos proprietários fundiários por outras políticas publicas setoriais (agrícola, florestal, de transportes, ...) é de natureza a contrariar os objetivos da política paisagística. A concorrência de incitações assim introduzidas se dobra ainda freqüentemente de uma concorrência de redes. Nos dois casos, a multifuncionalidade das atividades utilizando o espaço, com seu conceito associado de « junta de produção », está na base das dificuldades como das soluções (OCDE, 2000).

A junta de produção entre, por exemplo, a agricultura ou a floresta e a paisagem constitui a base do problema de coordenação. Por sua natureza, a paisagem é efetivamente afetada pelas decisões dos agentes econômicos que definem os usos do solo e a realização dos artefatos associados segundo uma lógica econômica que lhe é própria. Assim, as respostas que eles dão aos adversários do meio, em termos de reorganização, para otimizar a produção e maximizar a renda fundiária, sejam elas ao mesmo tempo criadoras da paisagem.

Entre essas limitações, são sem duvida, a encosta e alagamentos os mais produtivos de artefatos. Em todos os casos, as respostas dependem evidentemente da tecnologia utilizada, uma vez par a elaboração das reorganizações e pela exploração dos espaços rearranjados.

Assim, as superfícies de resposta usadas em encostas íngremes, geralmente é um terraço, utilizado em inúmeros parreirais, nos castanhais de Cevennes, nos vales do Himalaia ou nos arrozais das Filipinas. Ela exige um investimento importante em tempo de trabalho, ou em meios mecânicos, o que explica às vezes o abandono frequente desse modo de exploração desde que as condições do mercado sejam desfavoráveis, ou ao contrário as condições políticas retornem a serem favoráveis.

Nas regiões de grandes culturas mecanizadas, as encostas dos vales são abandonadas à floresta ou mato, já que a desproporção entre o custo de seu desenvolvimento e o ganho marginal retirado seria muito elevada. O conhecimento da água e dos alagamentos induz a uma grande variedade de paisagens e de artefatos, redes de diques e de canais, estações de elevação, de dispositivos originais de drenagem, como a represa de Montady, perto de Béziers, ou na "terraferma" de Veneza.

Esses trabalhos de desenvolvimento são geralmente fora do alcance de indivíduos ou de famílias isoladas, e clamam uma ação coletiva (no caso de comunidades monásticas da Idade Média, ou das associações de drenagem dos Países Baixos) ou de meios financeiros importantes, como no caso da conquistas de pântanos pela burguesia vietnamita, ou no caso dos reinados cambodjanos do século XII.

As políticas públicas que tem por objetivo apoiar a produção agrícola, ou a promoção das florestas, ou o desenvolvimento de uma rede de infra-estruturas de transportes em estradas têm efeitos externos sobre a paisagem, da mesma maneira que atores privados quando se trata de bens públicos ou indiretamente, quando se trata de incitar e de orientar a atividade dos agentes econômicos.

\section{COMO A PAC MODIFICA O MODO DE USO DO SOLO AGRÍCOLA?}

A Política Agrícola Comum (PAC) está na vanguarda das políticas setoriais que afetam a distribuição de terra e, portanto, a formação das paisagens. A figura 1 ilustra esse impacto na escala da produção agrícola. $\mathrm{O}$ agricultor decide a repartir suas terras entre dois usos: as culturas e os campos (esta simplificação se faz sem perda de generalidade). Ele escolherá racionalmente de repartir suas terras equalizando os aproveitamentos marginais (por ex. a margem bruta agrícola) de cada uso do solo. Esses aproveitamentos dependem das condições agronômicas, que determinam grandemente a produtividade dos solos, do preço relativo dos produtos agrícolas e dos preços dos insumos (sementes, mão de obra, pesticidas, etc.). As ajudas PAC às culturas vêm melhorar $\mathrm{o}$ aproveitamento marginal das culturas se bem que a apropriação das terras de exploração será feita em $x_{m}$, com uma maioridade de terras de cultura. Todavia, do ponto de vista social, é provável que os campos gerem externalidades positivas, principalmente por seu valor paisagístico. Ao inverso, as culturas demandam alguns aborrecimentos (corte de cercas vivas, resíduos de pesticidas, perda da biodiversidade, etc.). Do ponto de vista social, temos que levar em conta esses efeitos externos, já que para a sociedade, o aproveitamento ótimo das terras de exploração agrícola está em $x^{*}$. Através desse exemplo, vemos como a ausência de coordenação coletiva, devido à presença de externalidades e de uma política setorial, faz divergir o ótimo privado do ótimo social. Em valores, essa perda coletiva se situa no nosso exemplo na superfície demarcada da figura 1 . 


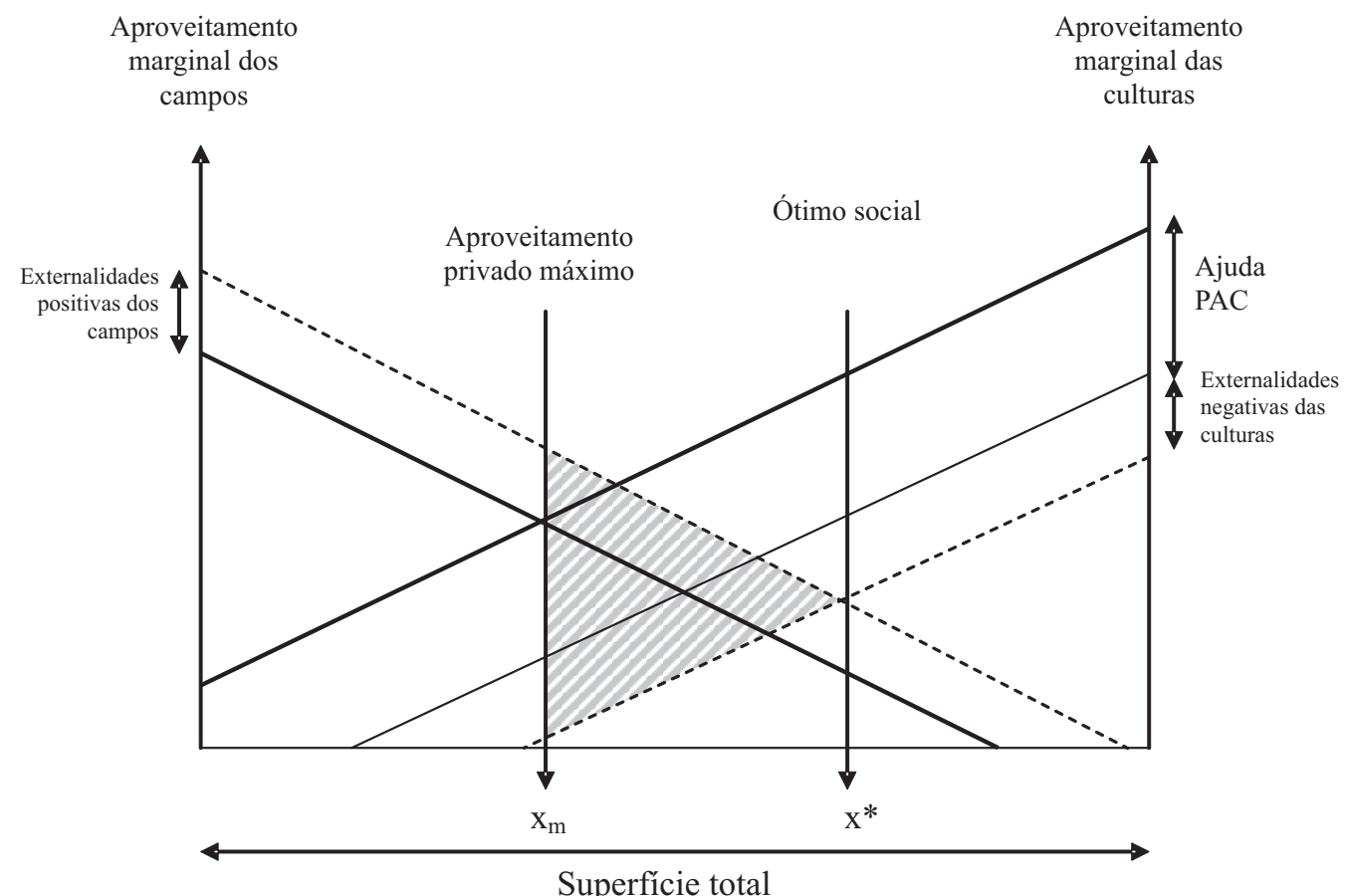

Figura 1. Apropriação do solo em presença de uma ajuda às culturas (Le Goffe, 2003).

\section{A PRODUÇ̃̃o CONJUNTA DA PAISAGEM}

Quando um bem público não pode ser produzido a não ser pela ação conjunta de um número importante de atores, falamos de produção conjunta. A natureza da relação entre as ações e o resultado agregado caracteriza a tecnologia de produção do bem público. Assim por exemplo, a segurança nas estradas (definida, por exemplo, pelo número de acidentes) é dependente do número de usuários da estrada que respeitem o código num dado momento ou durante um período de tempo. A relação funcional entre esse número e o nível de segurança na Estrada caracteriza a função de produção da segurança da estrada. Ela é raramente linear, e mais ainda de tipo logístico. De fato, distinguimos classicamente as tecnologias aditivas, as do tipo "elo fraco" e as do tipo "melhor tiro". Supondo que uma investigação e uma enquete pré-realizada tenham permitido de caracterizar a paisagem desejada pelos cidadãos, sejam os proprietários fundiários e outros detentores do direito ao uso que a autoridade deve direcionar para atingir esse resultado? Quer dizer, como, a partir de mudanças pontuais efetuadas numa escala de propriedades individuais, se obtém o resultado desejado em nível global da unidade paisagística? Esta questão está ligada àquela dos limiares da percepção.

A questão agora é a da escolha do instrumento ou do método que o projeto da paisagem ou a política paisagística pode utilizar, e a que nível?

A resposta merece ser desvendada de acordo com o que consideramos a diversidade de paisagens, onde a conservação e a gestão devem ser abordadas em nível nacional, e clama para esse fim de medidas nacionais, e a qualidade de uma paisagem local, para a qual os primeiros a se preocuparem são os membros da população local.

Levando em conta as dificuldades descritas acima, as incitações destinadas a promover certo tipo de paisagem riscam de ter pouco peso frente às incitações e restrições oferecidas pelas outras políticas setoriais. È então preferível utilizar uma via regulamentar, embora este último seja suscetível de reencontrar a oposição de portadores de uma concepção absolutista de direitos de propriedade, e mesmo que possua custos de transação mais elevados. Apesar disso, a regulamentação não pode encontrar sua plena eficácia caso ela não se apóie numa vontade coletiva forte. Por sua natureza econômica, às vezes recurso para a economia turística e quadro de vida para os habitantes, podemos pensar que a paisagem esta mesmo a motivar os eleitos locais e os cidadãos para suplementar as faltas de coordenação das políticas setoriais. No entanto, o nível local por si só não pode superar esses defeitos, e é desejável que as políticas comunitárias aproveitem sua conta de impactos sobre a paisagem, ou pelo menos permitem articular com os objetivos da paisagem local.

\section{CONCLUSÕES}

A paisagem é o tema das preferências individuais. É um recurso econômico para os territórios, contribuindo assim para o bem-estar social. Por conseguinte, é objeto de atenção de muitas partes interessadas, públicas e privadas.

Do ponto de vista da demanda e, em conseqüência da dificuldade de gerir a exclusão do acesso, a paisagem tem o caráter de um bom público local. As atividades humanas as transformam. Estas mudanças induzidas podem ser avaliadas em termos do seu impacto no bem-estar social, através de vários métodos mais ou menos satisfatórios (preferências reveladas ou declaradas) que ainda precisam ser exploradas e adaptadas. 
Enquanto as forças de aglomeração parecem consubstanciais com a economia urbana, as forças de dispersão industrial são características da formação das paisagens rurais. Eles se baseiam na natureza do processo de produção agrícola e florestal (precisam de uma área de coletor de energia solar, retornos decrescentes, as economias de escala reduzida, ...). A ação combinada de forças de aglomeração e forças de dispersão produz a dinâmica da paisagem. Mas os direitos de propriedade agem como forças viscosas, não só por causa dos custos diretos relacionados à modificação dos limites físicos, que estão intimamente ligados na matriz paisagística, mas também por causa de altos custos de transação associados com o processo expropriação ou de negociação e trocas voluntárias (como em terrenos de consolidação). Por esta razão, as paisagens têm uma história (suas transformações mostram uma dependência de estados anteriores). E esta característica é tanto constrangimento como uma oportunidade para a governança da paisagem.

A gestão da paisagem deve mobilizar metodologias e ferramentas que pertençam a diferentes registros de ação, uma vez que os procedimentos administrativos que regulam a atividade de gestão do estado e coletividades territoriais até aos instrumentos de regulação que visam enquadrar o exercício do direito de propriedade.

\section{REFERÊNCIAS}

CAVAILHÈS, J.; BROSSARD, T.; HILALL, M.; JOLY, D.; TOURNEUX, F.P.; TRITZ, C.; WAVRESK, P. Valeur des paysages ruraux et localisation résidentielle. In: AUBERT, F. ; PIVETEAU, V. ; SCHMITT, B. (eds). Agriculture, développement régional et politiques publiques. Quels enjeux pour l'action et pour la recherche ? Editions QUAE. 2007.

Le GOFFE, P. Multifonctionnalité des prairies : comment articuler marché et politiques publiques ? INRA Productions Animales, v.16, n.3, 175-182, 2003

LIFRAN, R.; OUESLATI, W. Elément d'économie du paysage. Economie rurale, n. 297-298, p. 85-98, 2007.
LUGINBUHL, Y. Pour un paysage du paysage. Economie rurale, n. 297-298, 2007, p 23-40.

LUGINBUHL, Y. Synthèse des résultats scientifiques. Programme de recherche Politiques Publiques du Paysage: analyse, évaluation et comparaison, Ministère de l'écologie, 2004. 22 p.

MARSHALL, E. Open-Space Amenities, Interacting Agents and Equilibrium Landscape Structure. Land Economics, v.80, n.2, 2004, p. 272-293.

OECD. Valuing rural Amenities. Paris, 2000. 180 p.

OUESLATI, W.; SALANIE, J.; BEAUJOUAN, V.; DELAÎTRE, C. Hedonic estimates of agriculture landscapes values in suburban areas. CONGRÉS DE EUROPEAN ASSOCIATION OF AGRICULTURAL ECONOMISTS, 12, 2008. Gent, Belgique, Actes... 2008a.

OUESLATI, W.; MADARIAGA, N.; SALANIÉ, J. Evaluation contingente d'aménités paysagères liées à un espace vert urbain. Revue d' Etudes en Agriculture et Environnement, v. 2, n. 86,2008 b.

PRICE, C. Landscape Economics. Macmillan, 1978. 192 p.

RAMBONILAZA, M. Evaluation de la demande de paysage: état de l'art réflexion sur la méthode du transfert des bénéfices. Cahiers d'Economie et Sociologie Rurales, 70, p. 77-101, 2004.

TURPIN, N.; OUESLATI, W. Landscape in the dynamics of local economies. Landscape Research, v.33, n.3, p.259-262, 2008.

WILLINGER, M. La méthode d'évaluation contingente : de l'observation à la construction des valeurs de préservation. Nature, Science et Société, janvier, 1996. 